\title{
Yüksek Hızlı Trenlerin Serbest Zemin Yüzeyinde Olușturduğu Titreşimlerin Deneysel ve Analitik Olarak Incelenmesi
}

\author{
Fatih Göktepe ${ }^{a}$, H. Serdar Küyük ${ }^{a, b}$, Erkan Çelebi ${ }^{a}$, Muharrem Aktaşa ${ }^{a}$ Elif Ağcakoca ${ }^{a}$ \\ ${ }^{a}$ Department of Civil Engineering, Engineering Faculty, Sakarya University, 54187 Sakarya, Turkey \\ ${ }^{b}$ Kandilli Observatory and Earthquake Engineering Institute, Bogazici University, 81220 Istanbul, Turkey
}

\begin{abstract}
Özet- Trenlerin seyahat hızlarının artması ve tekrarlı geçişleri, yüksek frekanslı dinamik yükleri meydana getirir. Titreşen demiryolu üstyapısı, titreşim enerjisini çevresindeki zeminlere iletir. Demiryolu ağına yakın bölgelerdeki yapılar zemin ortamının karakterine göre biçimlenen titreşimlerden etkilenir. Kuvvetli yer hareketleri binalara ve temellerine hasar verebileceği gibi binalarda yaşayan insanlara da konfor bozucu titreşimleriyle rahatsızlık verebilir. Türkiye'de taşıma gücü zayıf, alüvyon zemin ve yoğun yerleşim bölgelerinden geçen (Eskişehir-Adapazarıİzmit), inşaatı devam eden ve geçirilmesi planlanan yüksek hızlı trenler'in (YHT) çevrede oluşturdukları titreşimlerin tespiti için şuana kadar herhangi bir saha araştırması yapılmamıştır. Bu çalışmanın amacı, YHT'lerin yakın çevrede oluşturduğu titreşimleri doğal saha koşullarında belirlemektir. YHT demiryolu hattına yakın seçilmiş gözlem noktalarında, YHT trafiğinin ürettiği kuvvetli zemin titreşimleri yedi yüksek kaliteli sismik sensör ile kayıt altına alınmış ve titreşimlerin oluşturdukları pik ivme değerlerinin mesafeyle azalımı hesaplanmıştır. Saha çalışması sonuçları, Bornitz'in iki nokta arasındaki enerji azalımı ile ilgili olarak sunmuş olduğu analitik çözüm ile karşılaştırılmıştır. Analitik yöntemin serbest zemin yüzeyinde oluşan düşey ivme genliklerini tahmin etmede başarılı olduğu fakat yatay ivme kayıtları için fazla kestirim yaptığı bulunmuştur.
\end{abstract}

Anahtar Kelimeler: Yüksek hızlı tren, serbest zemin titreşimleri, yerinde zemin titreşim ölçümleri

Abstract- Railway platform which is vibrated with higher
frequency dynamic loads induced by high speed train cars transfer
these vibrations energies to surrounding ground and close by
structures are effected by them. Strong ground motion not only
can give damage to the nearby buildings and their footings but also
effect the human comfort by undesired vibrations. Extensive in-
situ research are still required for both recent ongoing
construction projects in soft soil deposits (Eskişehir-Adapazar-
Izmit) and for planned construction projects on highly populated
areas (Edirne-Istanbul-Ankara-Kars) in Turkey. The aim of the
study can be summarized as to determine comfort disturbance and
devastating environmental vibration created by high speed trains
on free field. Strong ground motions induced by high speed train
measured and recorded at the inspection points selected at the site
close to high speed train line passing through highly populated
regions. Environmental effects of these vibration data compared
and evaluated. However, the applicability of a well know half space
solutions based on Bornitz's analytical approach which takes
account the loss of the amplitude of waves due to geometrical
damping and material damping of Rayleigh waves are investigated. Bornitz's solution tends to overlap vertical free field vibration with in-situ measured records.

Index Terms - High speed train, free field vibrations, in situ measurement

\section{GİRİ̧}

Con zamanlarda küresel dünyada, hareket hızlarını, yolcu ve yük kapasitelerini sürekli arttırarak değiştiren YHT teknolojisi araştırmalarının önemli bir bölümü yalnızca yolcuların konforunu sağlamak için değil aynı zamanda demiryolu ağının içinden geçtiği yoğun yerleşim bölgelerinde yaşayanların maruz kalabileceği gürültü kirliliğinden ve büyük genlikli titreşimlerden korunması çalışmalarını da kapsamaktadır. İnsanların hayat standartlarının ekonomik gelişmeye bağlı yükselmesiyle modern kent topluluklarının yoğun yerleşim bölgelerinde, daha kaliteli, güvenli yaşam isteği ve çevresel etkenlerin ürettiği problemlere karşı gösterdikleri duyarlılıklar hızla artmaktadır. Deprem yer hareketi dışındaki insan yapısı üretilen yüksek frekanslı titreşim kaynaklarının (ağır makine temelleri, yoğun ve hızlı trafik akış yükleri, masif inşaat aktiviteleri, patlamalar vb.) oluşturduğu kuvvetli dalgaların yumuşak zemin ortamında yayılışının incelenmesi, çevresel titreşim problemlerinin mühendislik çözümlerinin üretilmesi açısından önem kazanmıştır [1-5].

Durağan veya hareketli titreşim kaynaklarının ürettiği kuvvetli yüzey dalgalarının sebep olduğu büyük genlikli titreşimlerin davranışını ve yakın çevresindeki etkilerini daha iyi anlayabilmek için son dönemlerde az sayıda da olsa deneysel saha araştırmaları gerçekleştirilmiştir. Yüksek hızlı demiryolu taşımacılığının kent içinde ürettiği çevresel titreşimlerin etkileri, trafik akış yoğunluklarına, tren seti yüklerine, etkime sürelerine ve seyahat hılarına bağlı incelenmiş ve dalga yayılımı probleminin anlaşılabilmesiyle ilgili birçok saha deneyleri gerçekleştirilmiştir. Degrande ve Schillemans [6] Brüksel-Paris arasında test sürüşü yapan bir lokomotif ve 7 vagondan oluşan Thalys HST tipi YHT'nin 223$314 \mathrm{~km} /$ saat arasındaki geçiş hızlarında demiryolu ve yakın çevrede (4-72 $\mathrm{m}$ arasında 14 farklı gözlem noktası) oluşturdukları serbest zemin titreşimlerini incelemişlerdir. Diğer taraftan, Branderhorst [7] Hollanda'nın Amsterdam- 
Utrecht şehirleri arasında 40-160 km/h hızlarında seyahat eden aynı tip YHT'nin meydana getirdiği çevresel titreşimleri ölçerek, elde ettikleri veri setini sayısal modellerin doğrulanmasında kullanılmak üzere araştırmacılara sunmuşlardır. Bununla birlikte, Auersch [8] Almanya'da faaliyet gösteren ICE tipi YHT'nin 100-300 km/h arasinda değişen hızlarda elde ettiği ölçüm sonuçlarını rapor olarak yayınlamıştır. Aynı şekilde Adolfssson vd. [9] İsveç'in batı sahil hattında Göteborg-Malmö arasında kullanılan X2000 tipi trenlerin $200 \mathrm{~km} / \mathrm{saat}$ aşan hızda oluşturduğu çevresel titreşimleri kayıt altına almışlardır. Titreşim etkilerini kapsayan çevresel değerlendirme sonuçları yeni ulaşım sistemlerinin tasarımı ve planlanması aşamasında gerekli programlardan biri haline gelmiştir.

Yüksek hızlı demiryolu taşımacılığına sahip birçok Avrupa ülkesinde olduğu gibi, ülkemizde de yolcu taşımacıllğındaki trafik akış hızları $\mathrm{V}=250 \mathrm{~km} / \mathrm{h}$ değerlerine ulaşacak şekilde planlanmış, yolcu ve yük taşımacılığındaki dingil yükleri 180$225 \mathrm{kN}$ olarak tasarlanmıştır. Yüksek-hızlı demiryolu hatlarında sürekli tren geçişlerinin, demiryolu üstyapısında, çevre zeminde ve yapılarda oluşturduğu kuvvetli titreşimlerin ölçülmesi, uluslararası normlara göre karşılaştırılıp incelenmesi, yapı temellerinde hasar ve insanlarda rahatsızlık verici etkilerinin değerlendirilmesi, titreşimlerin yayılma alanında veya korunacak yapı çevresinde azaltılması ve en uygun demiryolu üstyapı tasarımının gerçekleştirilmesi gibi konular inşaat mühendisliğinin ulaşım sistemlerinin planlanmasında önemli bir uğraş alanı olmuştur.

Ülkemizde demiryolu ulaşım sistemlerini ilgilendiren konularda gerçekleştirilen az sayıdaki saha araştırma çalışmaları kent içi hafif raylı sistem titreşimlerinin yolcu konforu ve güvenliği üzerindeki etkilerinin incelenmesiyle, seyahat kalitesinin ve çevresel akustik sorunların iyileştirilmesiyle sınırlı kalmıştır. Ulusal literatürde önerdiğimiz proje konusuna en yakın çalışma, İstanbul Aksaray-Havalimanı şehir içi raylı ulaşım trafiğinde kullanılan ve maksimum seyahat hızları $50 \mathrm{~km} / \mathrm{saat}^{\prime} \mathrm{i}$ aşmayan hafif metro araçlarının geçişleri sırasında demiryolu hattında ve $9.5 \mathrm{~m}$ yakınındaki bir idari binada oluşturduğu titreşim etkilerinin ölçüldüğü ve konfor analizi yapılarak değerlendirildiği yerel çalışmadır [10]. Aynı projede gerçekleştirilen ölçümler ve simülasyon çalışmaları, taşıt tekerleği-ray etkileşimi sonucu çevreye yayılan konfor bozucu titreşimleri ve gürültüyü azaltmak için araç gövdesinde ve demiryolu alt yapısında alınabilecek izolasyon yöntemlerine odaklanmıştır. Çözüm önerileri ağırlıklı olarak makine mühendisliği disiplini çerçevesinden sunulmuştur. Çalışmada, demiryolu hattına 3.5 $\mathrm{m}$ uzaklıkta bulunan ve derinliği sadece $1 \mathrm{~m}$ olan drenaj amaçlı açık bir kanal uygulamasının zemin titreşimleri üzerindeki azaltıcı etkisi ölçülmüştür. Diğer taraftan, ülkemizde Çelebi vd. [11] gerçekleştirmiş oldukları saha deneylerinde, harmonik titreşim dalgaları oluşturmak için 10-100 Hz frekans aralığında çalışan $250 \mathrm{~N}$ düşey yük kapasiteli elektro-dinamik sarsıcı kullanılmıştır. Çalışmada küçük ölçekte (boyutları:1x1x0.5m) hazırlanan betonarme temellerin titreşimleri, önlerine $2.5 \mathrm{~m}$ derinlikte yerleştirilen dalga bariyerinin (kesit alanı $=3 \mathrm{~m}^{2}$ ) aktif ve pasif uygulamalarıyla birlikte incelenmiştir.

Yukarıda tanımlanan problemlerin çözümlerine yönelik kapsamlı saha araştırmalarının gerekliliği özellikle ülkemizin taşıma gücü zayıf, alüvyon zemin ortamlarından (EskişehirAdapazarı-İzmit) ve yoğun yerleşim bölgelerinden geçen, inşaatı devam eden ve geçirilmesi planlanan yüksek hızlı modern demiryolu hatları (Kars-Ankara-İstanbul-Edirne hızlı tren projesi) için güncelliğini korumaktadır. Ülkemizde YHT yolcu taşımacılığının yakın zamanda faaliyete geçmiş olması ve ulaşım sisteminin yeni olması, söz konusu muhtemel çevresel sorunların öngörülememesi, mevcut araştırmaların da sadece demiryolu üstyap1 titreşimleri ve gürültü kirliliğinin azaltılmasına odaklanmış olması, bu çalışmayı çevresel titreşimlerin yerinde incelenmesi konusuna yönlendirmiştir. $\mathrm{Bu}$ çalışmada demiryolu hattına çok yakın seçilmiş bir sahada serbest zemin titreşimleri kayıt altına alınmış ve YHT trafiğinin ürettiği zemin titreşimlerinin mesafe ile azalımı incelenmiştir.

\section{SAHA KOŞULLARI VE YÜKSEK HIZLI TREN SETININ GENEL} ÖZELLIKLERI

$\mathrm{Bu}$ çalışma kapsamında, İstanbul-Ankara arasında toplam uzunluğu $533 \mathrm{~km}$ olan, taşıma gücü zayıf alüvyon zemin ortamlarından ve yoğun yerleşim bölgelerinden geçen Köseköy-Pamukova arasındaki yüksek hızlı modern demiryolu hattındaki YHT geçişleri dikkate alınmıştır (Şekil 1). YHT geçişlerinin yakın çevrede oluşturduğu titreşim etkilerinin yerinde incelenebilmesi için ölçüm sahası olarak İzmit-Arifiye arasında bulunan Kırkpınar bölgesi seçilmiştir (Şekil 2). Demiryolu trafik akış hızının 200-230 km/saat gibi yüksek değere ulaştığı güzergah oldukça zayıf zemin koşullarına (zemin kayma dalga hızı $<300 \mathrm{~km} / \mathrm{saat}$ ) sahiptir.

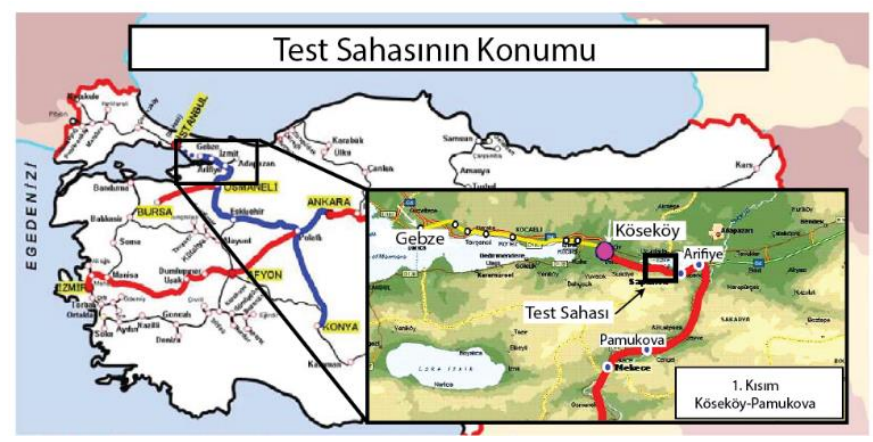

Şekil 1. Yapımı bitmiş ve yapılması planlanan yüksek hızlı tren hatları ve bu çalışmanın yapıldı ı̆ı test sahası 

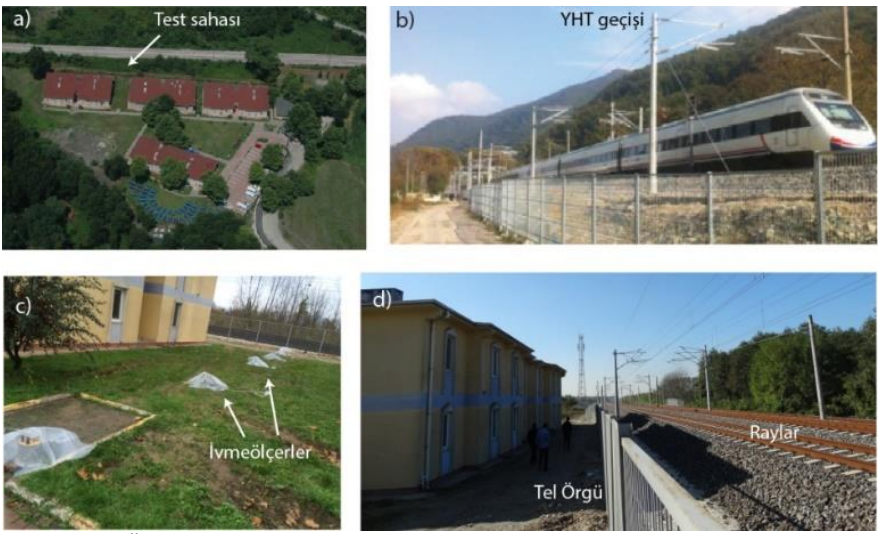

Şekil 2. Ölçüm alınan serbest zemin bölgesine ilişkin detaylar

TCDD'nın yüksek hızlı demiryolu yolcu taşımacılığında kullandığı HT65000 YHT seti ve güzergah kesiti ile ilgili bilgiler Şekil 3'de verilmiştir. Yolcu vagonlarını çeken lokomotif 27.4 metre uzunluğundadır. Tekerlekler arası mesafe 2.8 metredir. YHT toplamda 6 vagonla birlikte 159 metre uzunluğa ulaşarak yüksek hızda hareket eden ağır bir kütleye dönüşmektedir. Yolcu durumuna göre 2 vagon daha eklenebilmektedir. Bu tren seti 36 metrelik UIC-60 ray altında ön-germeli, önçekmeli monoblok B70 traversler üzerinde hareket etmektedir. Demiryolunun taşıtı ve hattının mekanik özellikleri Tablo 1'de verilmiştir. Maksimum insan kapasitesi 411 ve katar yükü 18 tona kadar çıkabilmektedir. Yolcu taşımacılığında $250 \mathrm{~km} / \mathrm{saat}$ hıza ulaşabilen tren seti incelenen bölgede $\approx 230 \mathrm{~km} / \mathrm{saat}$ ile geçmektedir. Tren güzergâhının kesit bilgiler Şekil 3b' de gösterilmiştir.

a)

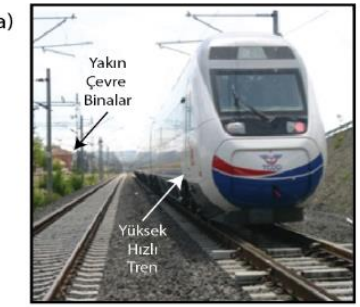

c)

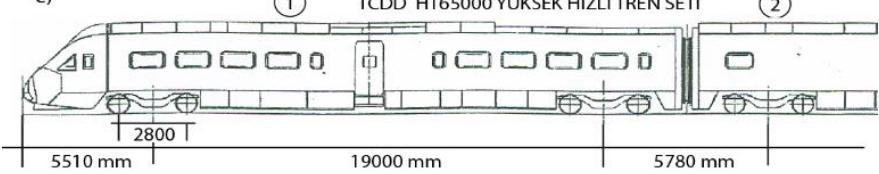

Şekil 3. İncelenen test sahasından geçen yüksek hızlı tren a) önden görünüşü

b) geçtiği güzergâhın kesit bilgileri c) HT65000 yüksek hızlı tren setinin boyutlar
TABLO 1 DEMIRYOLU TAȘITI VE HATTININ MEKANIK ÖZELLIKLERI [12]

\begin{tabular}{llccc}
\hline Bileşenler & Karakteristikler & Semboller & Büyüklük & Birim \\
\hline Lokomotif & Dingil yükü & $F_{z}$ & 180 & $\mathrm{kN}$ \\
HT 65000 & Hareket hızları & $V$ & 69,44 & $\mathrm{~m} / \mathrm{sn}$ \\
\hline Demiryolu & & & & \\
2UIC 60 & & & & \\
\hline & Kesit alanı & $A_{r}$ & $1.54 \times 10^{-2}$ & $\mathrm{~m}^{2}$ \\
& Atalet momenti & $I_{z}$ & $6.11 \times 10^{-5}$ & $\mathrm{~m}^{4}$ \\
& Elastisite modulü & $E$ & $2.11 \times 10^{8}$ & $\mathrm{kN} / \mathrm{m}^{2}$ \\
& Birim hacim & $\gamma$ & 78 & $\mathrm{kN} / \mathrm{m}^{3}$ \\
ağırlık & & & & \\
\hline Balast & & & & \\
Yay-söndürücü & Rijitlik katsayıs1 & $k_{b}$ & $1.26 \times 10^{5}$ & $\mathrm{kN} / \mathrm{m}$ \\
sistem & Sönüm katsay1s1 & $c_{b}$ & $1.69 \times 10^{2}$ & $\mathrm{kNsn} / \mathrm{m}$ \\
\hline & & & &
\end{tabular}

\section{CALISMADA KULLANILAN SENSÖRLER}

Çalışma kapsamında kullanılan ivmeölçerler çok düşük gürültü seviyelerine sahip, üç eksenli Capacitive Force Micromachined sensörler ile zayıf titreşim hareketlerini ölçebilen, DAC-3HDG tipi 32 bit yüksek çözünürlüklü ivmeölçerlerdir. Saha ölçümlerinde kullanılacak olan cihazlar: GPS anteni, enerji kaynağı ve ivmeölçer ana kutusu olmak üzere üç temel parçadan oluşmaktadır (Şekil 4). GPS anteni ve enerji kabloları ivmeölçere iki kablo yardımı ile bağlanırlar. Ana kutunun içinde üç tane MEMS sensörü, ADC sayısallaştırıcı ve ivmelerin kayıt altına alındığı bellek vardır. Bu sensörlerden yedi takım test sahasında kullanılmıştır.

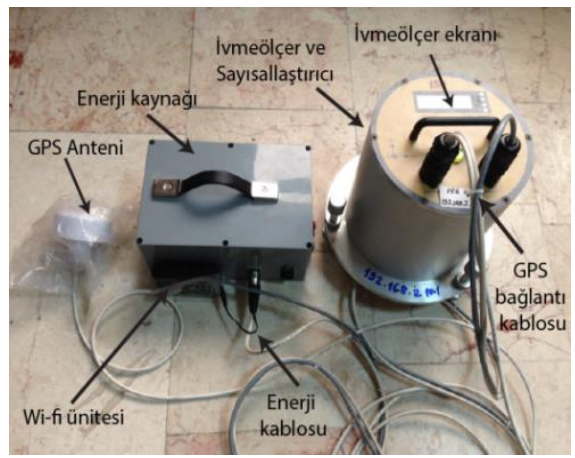

Şekil 4. DAC-3HDG GPS senkronizasyonlu sayısallaştırıcı ve veri kaydedici ivmeölçer

\section{DOĞAL SAHA KOȘULLARINDA SERBEST ZEMIN TITREŞIMLERININ ÖLÇÜLMESİ}

Kernel Yüksek hızlı demiryolu hattına yakın seçilmiş ölçüm sahası, Sakarya'nın Sapanca ilçesinde bulunan SAÜ Kırkpınar turizm MYO uygulama oteli ve sosyal tesislerinin bulunduğu yerleşkedir. Yerel zemin koşullarını dikkate alarak 200-230 $\mathrm{km} / \mathrm{saat}$ hız aralığındaki tren geçişlerinin ürettiği serbest yüzey yer hareketini dalga oluşum mekanizmasına bağl incelemek ve zemin formasyonunun dalga iletimi üzerindeki etkisini değerlendirmek için $3.5 \mathrm{~m} \leq \mathrm{L} \leq 4.75 \mathrm{~m}$ aralıklarla güzergâha sistematik olarak dik dizilmiş yedi gözlem noktasında titreşim 
kaydı alınmıştır. Titreşim etkilerinin kayıt altına alındığı gözlem noktalarının konumu Şekil 5'de gösterilmiștir. İstanbul'dan çıkıp Ankara'ya giden YHT'ler Şekil 5a'daki sağ rayı kullanmaktadır. Güvenlik sebebi ile tel örgünün YHT tarafına sensör koyulamamıştır. İlk sensör YHT demiryolu hattından 4.8 metre uzağa, son sensör ise 31 metre uzağa konulmuştur. Alınan kayıtlar üç bileşenli olup, sensörler YHT güzergâhına paralel (X ekseni) olacak şekilde yerleştirilmiştir.

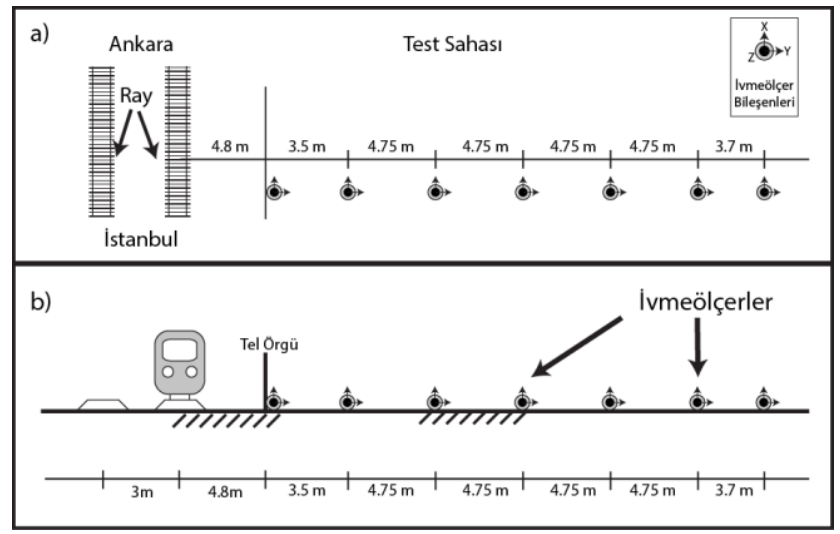

Şekil 5. İncelenecek test sahasının doğal saha koşullarındaki a) plan ve b) kesit görünüşleri

TABLO 2. DINAMIK YÜK KAYNAĞINA OLAN MESAFEYE BAĞLI HER ÜÇ BIILEŞENDE ÖLÇÜLEN SERBEST ZEMIN TITREŞIMLERINNE AITT IVME DEĞERLERİ

\begin{tabular}{|c|c|c|c|}
\hline $\begin{array}{l}\text { Dinamik } \\
\text { yük } \\
\text { kaynağına } \\
\text { olan } \\
\text { mesafe } \\
\text { (m) }\end{array}$ & $\begin{array}{c}\text { X bileşeninde } \\
\text { ölçülen ivme değeri } \\
(\mathrm{cm} / \mathrm{s} / \mathrm{s})\end{array}$ & $\begin{array}{c}\text { Y bileşeninde } \\
\text { ölçülen ivme } \\
\text { değeri } \\
(\mathrm{cm} / \mathrm{s} / \mathrm{s})\end{array}$ & $\begin{array}{c}Z \\
\text { bileşeninde } \\
\text { ölçülen } \\
\text { ivme değeri } \\
(\mathrm{cm} / \mathrm{s} / \mathbf{s})\end{array}$ \\
\hline 4.8 & 57.0938 & 35.2439 & 18.2653 \\
\hline 8.3 & 19.6206 & 13.0662 & 10.0833 \\
\hline 13.1 & 9.4852 & 5.8467 & 8.2158 \\
\hline 17.8 & 2.8653 & 5.0233 & 6.0167 \\
\hline 22.6 & 3.6351 & 3.3199 & 4.1601 \\
\hline 27.3 & 9.4079 & 9.7046 & 2.9858 \\
\hline 31.0 & 3.5710 & 6.4255 & 3.2005 \\
\hline
\end{tabular}

Serbest zemin titreşimlerine ait ivme-zaman grafikleri

Demiryolu hattına yakın seçilmiş gözlem noktalarında, YHT trafiğinin ürettiği kuvvetli zemin titreşimleri yerinde ölçülerek kayıt altına alınmıştır. Gözlem noktalarında $X, Y$ ve $Z$ bileşenlerine ait ölçülen pik yer ivme değerleri, demiryolu güzergâhına olan mesafeye bağlı olarak Tablo 2'de verilmiştir. Geliştirilen yazılım yardımıyla her üç bileşen için (X, Y, Z) ivme değerlerinin zamana bağlı değişimi aşağıda grafikler halinde verilmiştir (Şekil 6, 7, 8). Grafiklerde X ekseni zamanı $\mathrm{Y}$ ekseni ise normalize edilmiş ivme genliklerini göstermektedir. Demiryolu hattına en yakın noktadan uzaklaşıldıkça serbest zemin yüzeyinde meydana gelen ivme değerlerinin azalmakta olduğu ve pik ivme değerlerinin güzergâha paralel doğrultuda gerçekleştiği tespit edilmiştir.
Demiryolu hattına paralel doğrultuda ölçülen ivme genlik bileşenlerinin, güzergâha dik doğrultudaki genlik bileşenlerine göre daha fazla olduğu gözlemlenmiştir. Fakat bu fark, mesafe ile azalmaktadır. Bununla birlikte düşey genlik bileşenlerinin, yatay genlik bileşenlerine göre yakın mesafelerde çok daha küçük ve mesafeyle daha yavaş bir şekilde azaldığı görülmüştür.

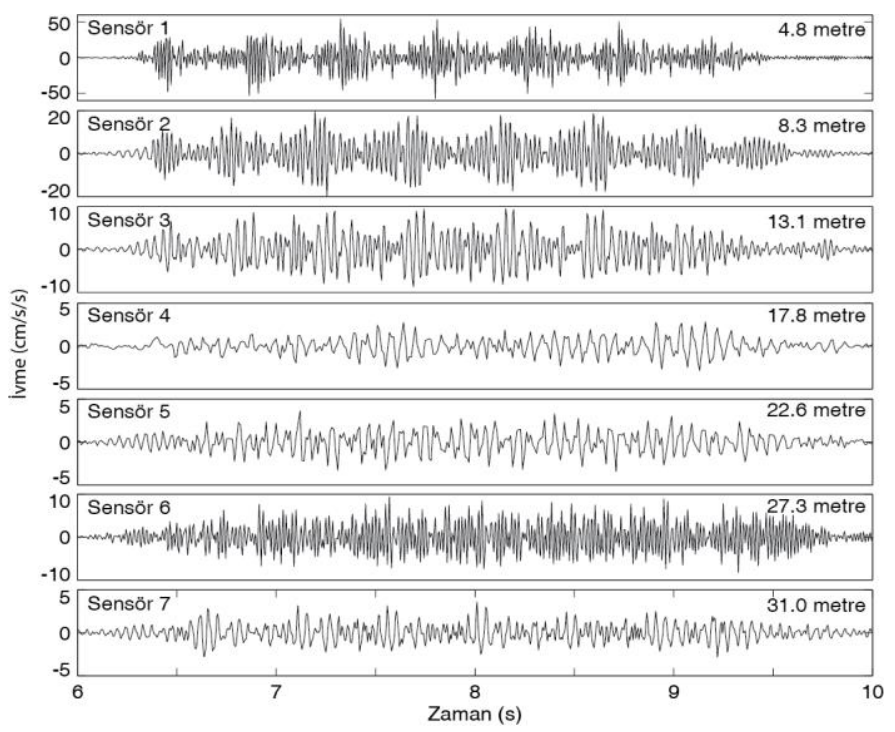

Şekil 6. Demiryolu hattına paralel doğrultuda (X bileşeni) ölçülen serbest zemin titreşimlerine ait ivme-zaman grafiğ $i$

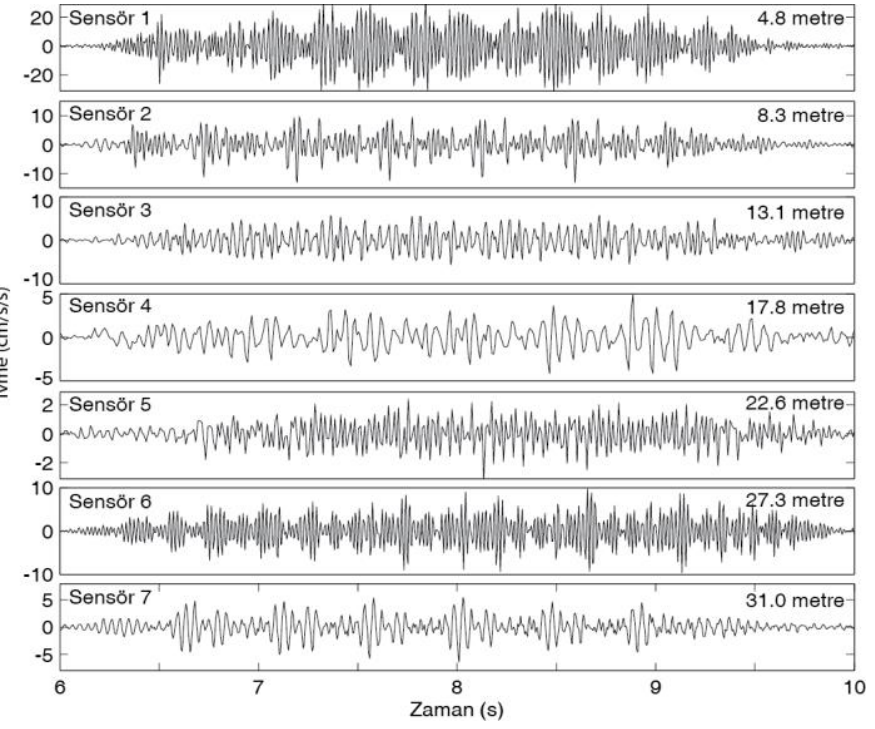

Şekil 7. Demiryolu hattına dik doğrultuda (Y bileşeni) ölçülen serbest zemin titreşimlerine ait ivme-zaman grafiği 


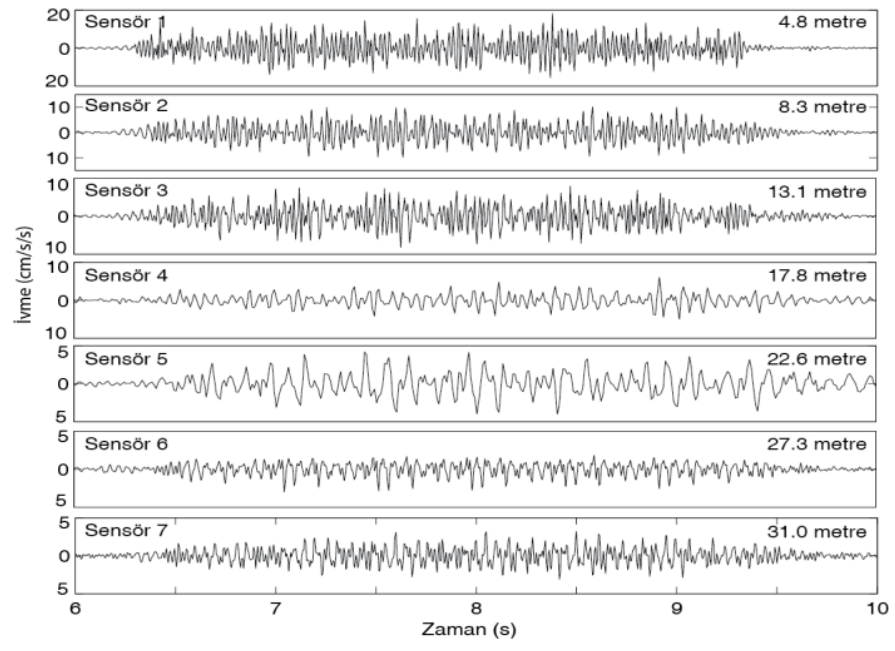

Şekil 8. Düşey doğrultuda (Z bileşeni) ölçülen serbest zemin titreşimlerine ait ivme-zaman grafiği

Elde edilen arazi ölçüm sonuçlarının analitik çözümle karşılaştırılmasi:

Amick ve Gendreau [13] tarafından geliştirilen ve Bornitz'in iki nokta arasındaki enerji azalımı ile ilgili olarak sunmuş olduğu analitik çözüme göre, geometrik ve malzeme sönümünün titreşim genliklerinde neden olduğu azalım aşağıdaki denklem kullanılarak ifade edilmektedir.

$u_{b}=u_{a}\left(\frac{r_{a}}{r_{b}}\right)^{\gamma} e^{\alpha\left(r_{a}-r_{b}\right)}$

Buna göre, yük kaynăğından $r_{b}$ mesafesindeki titreşim genliği $u_{b}$ ile, $r_{a}$ mesafesindeki titreşim genliği ise $u_{a}$ ile ifade edilmektedir. Denklemdeki, $\gamma$ geometrik azalım katsayısı olup, dış yükün neden olduğu sismik dalga yayılım mekanizmasına ve diş yükün pozisyonuna bağlı olarak Tablo 3'den seçilmektedir.

TABlo 3. DALGa tipine BAĞLI OLARAK TEORIK GEOMETRIK AZALIM KATSAYILARI [14]

\begin{tabular}{clcl}
\hline Yük Kaynağı & Dalga Tipi & Ölçüm Noktası & $\gamma$ \\
\hline Yüzeysel & Rayleigh & Yüzey & 0.5 \\
Yüzeysel & Body & Yüzey & 1 \\
Derin & Body & Yüzey & 1 \\
Derin & Body & Derin & 1 \\
\hline
\end{tabular}

$\alpha$ ile gösterilen malzeme azalım katsayısı ise, zeminin tipine ve diş yükün frekans içeriğine bağlı olarak aşağıdaki formülasyon kullanılarak hesaplanmaktadır.

$$
\alpha=\frac{2 \pi f D}{V_{R}}
$$

Demiryolu hattına dik bir biçimde yerleştirilen ivmeölçerler yardımıyla elde edilen serbest zemin yüzeyi titreşimleri ile Bornitz'in iki nokta arasındaki enerji azalımı ile ilgili olarak sunmuş olduğu analitik çözüm kullanılarak yapılan karşılaştırma Şekil 9'da verilmiştir. Grafikte x ekseni sensörlerin mesafesini, y ekseni ise ölçülen pik ivme değerlerini göstermektedir. Özellikle en yakın iki sensörün genlik yatay bileşenleri, düşey ölçüme göre çok daha büyük değere sahiptir. Ölçülen ivme değerlerinin mesafeye bağlı değişimi incelendiğinde, analitik yöntem ile serbest zemin yüzeyinde elde edilen ivme genliklerinin düşey bileşeni ile büyük mertebede örtüştügüu, buna karşın yatay bileşenlerde genellikle daha yüksek genlik değerleri verdiği tespit edilmiştir. Yatay $\mathrm{X}$ ve $\mathrm{Y}$ bileşenlerindeki 6 . sensörde okunan değerlerin yüksek çıkmasının sebebi, sensörün serbest zemin yerine yürüyüş patikasının üzerine konulmasından kaynaklanmaktadır (Şekil $3 c$ en soldaki sensör). Elde edilen sonuçlar Kuyuk vd. [15] Adapazarı-Arifiye hattında yaptıkları çalışmayla büyük ölçüde örtüştüğü düşünülmektedir.

Şekil 9. Elde edilen arazi ölçüm sonuçlarının analitik çözümle karşılaştırılması

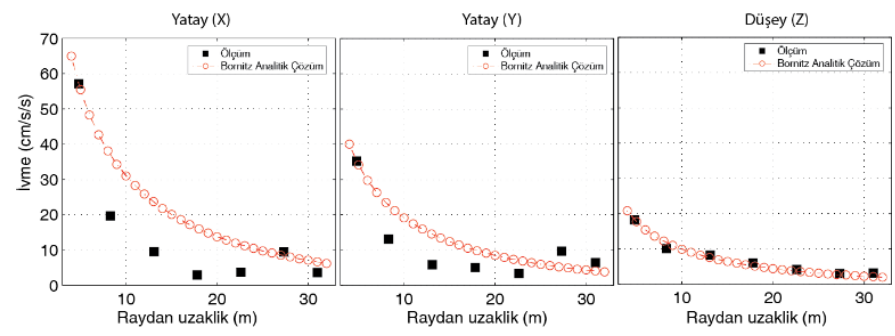

the change in the pixel values for the background for incoming frames can easily be detected. The estimated models can be adapted to the recent scene by using only most recent observations. On the other hand, using limited number of observations may not provide high-quality approximations for building models. The trade off between adaptiveness of the algorithm and robustness of the models can be balanced depending on the application. The details of the proposed framework are explained in the next section.

\section{SONUÇLAR}

The Tren setlerinin yüksek seyahat hızlarıyla tekrarlı geçişleri sırasında ürettikleri yüksek frekanslı dinamik yükler ile titreşen demiryolu üstyapısı, bu titreşim enerjisini çevresindeki zeminlere iletirler. Demiryolu hattına yakın çevre binalarda yaşayan insanların güvenliği ve konfor algısı dikkate alındığında, serbest zemin yüzeyinin farklı gözlem noktalarından YHT geçişleri esnasında oluşan titreşim problemlerinin yumuşak zemin koşullarında dalga yayılımı açısından deneysel olarak incelenmesi bu çalışmanın önemini ortaya koymaktadır. Bu çalışma sonucunda demiryolu hattına paralel doğrultuda ölçülen ivme genlikleri, güzergaha dik doğrultudaki bileşen genliklerine göre daha fazla olduğu gözlemlenmiştir. Bununla birlikte, Bornitz'in iki nokta arasındaki enerji azalımı ile ilgili olarak sunmuş olduğu analitik formülasyon kullanılarak yapılan karşılaştırmada, analitik yöntem ile serbest zemin yüzeyinde elde edilen ivme genliklerinin azalımında düşey bileşen ile büyük mertebede örtüştüğü, buna karşın yatay bileşenlerde genellikle daha 
yüksek genlik değerleri verdiği tespit edilmiştir.

\section{KAYNAKLAR}

[1] M. Bata 1971. "Effects on buildings of vibrations caused by traffic", Building Science, Vol.6, No.4, pp. 221-246.

[2] K. R. Massarsch, "Man-made vibrations and solutions", State-of the-Art Lecture, Third International Conference on Case Histories in Geotechnical Engineering, St. Louis, Missouri, U.S.A., II, 1393-1405, 1993.

[3] K. R. Massarsch, "Mitigation of traffic-induced ground vibrations", Keynote Lecture, 11th International Conference on Soil Dynamics and Earthquake Engineering and 3rd on Earthquake Geotechnical Engineering, University of California, Berkeley, U.S.A, 2004.

[4] H. Xia, Y. Cao, G. De Roeck, G. Degrande, "Environmental problems of vibrations induced by railway traffic", Frontiers of Architecture and Civil Engineering in China, Vol.1, No.2, pp. 142-152, 2007.

[5] F. Göktepe, "Yüksek Hızlı Trenlerin Çevre Yapılarda Oluşturduğu Titreşimlerin Önlenmesi İçin Bariyer Sistemlerin Etkinliğinin Parametrik Olarak İncelenmesi”, Doktora Tezi, Sakarya Üniversitesi, Fen Bilimleri Enstitüsü, Sakarya, Türkiye, 2013.

[6] G. Degrande, L. Schillemans, "Free field vibrations during the passage of a Thalys HST at variable speed", Journal of Sound and Vibration, Vol. 247, No.1, pp.131-144, 2001.

[7]J.Branderhorst, "Modellen voor het boeggolfprobleem bij hogesnelheidstreinen. Ontwerp en validatie met behulp van de resultaten van de proef Amsterdam-Utrecht", Master's Thesis, University of Twente, Enschede, Netherlands, 1997.

[8]L.Auersch, Forschungsbericht 155, Bundesanstalt für Materialforschung und-prüfung, Berlin, Zur Entstehung und Ausbreitung von Schienenverkehrserschutterungen-theoretische Untersuchungen und Messungen an Hochgeschwindigkeitszug Intercity Experimental, 1989.

[9] K. Adolfsson, B. Andréasson,, P-E. Bengtson, A. Bodare, C. Madshus, R Massarsch, G. Wallmark,, P. Zackrisson, "High speed lines on soft ground. Evaluation and analyses of measurements from the West Coast Line", Technical Report, Banverket, Sweden, 1999.

[10] R. Güçlü, M. Metin, H. Yazıcı, N.S. Yalçın,"Raylı Sistem Titreşimlerinin Yolcu ve Çevre Üzerindeki Etkilerinin İncelenmesi", TÜBITTAK 1001 Bilimsel ve Teknolojik Araştırma Projesi, MAG, Proje No: 106M443, 20072010.

[11] E. Çelebi, S. Fırat, G. Beyhan, İ. Çankaya, İ. Vural, O. Kırtel, “Field experiments on wave propagations and vibration isolation by using wave barriers", Soil Dynamics and Earthquake Engineering, Vol.29, No.5, pp. 824-833,2009.

[12] Z. Öztürk, V. Arlı, Demiryolu Mühendisliği, İstanbul: ATM, 2009.

[13] H. Amick,, M. Gendreau, "Construction vibrations and their impact on vibration sensitive facilities", ASCE Construction Congress 6, Orlando, Florida USA, 2000.

[14] D-S. Kim, J-S. Lee, "Source and attenuation characteristics of various ground vibrations", Geotechnical Earthquake Engineering, Soil Dynamics III., Geotechnical Special Publication ASCE, Vol.75, No.2, pp. 1507-1517, 1998.

[15] H. S. Kuyuk, F. Goktepe, E. Celebi, M. Aktas, E. Agcakoca, "Experimental study on liquid-storage tank and free field soil vibrations due to railway traffic", in GEOTECHNICAL ENGINEERING: International Civil Engineering \& Architecture Symposiumfor Academicians (ICESA), 145-157, Antalya, Turkey, 2014. 